\title{
Efficacy of garlic extract and yeast against Penicillium digitatum causing post harvest fruit rot of citrus (Citrus sisnensis L.)
}

\author{
R.P. SHINDE*, B.G. BARHATE AND N.A. MUSMADE \\ Department of Plant Pathology, Mahatma Phule Krishi Vidyapeeth, Rahuri, AHMEDNAGAR (M.S.) INDIA
}

\section{ARITCLE INFO}

Received : 29.06 .2016

Revised : 17.08 .2016

Accepted : 01.09.2016

\section{KEY WORDS :}

Citrus, Penicillium digitatum, Garlic extract, Yeast

\begin{abstract}
Freshly prepared 1 per cent garlic extract and 5 per cent yeast solution were tested against Penicillium digitatum causing fruit rot (green mold) of sweet orange both under in vitro and in vivo. 1 per cent garlic extract gives 15.7 per cent control and 5 per cent yeast gives 15 per cent control against Penicillium digitatum. Artificially inoculated fruits treated with 1 per cent G. E. were observed in good condition upto 35 days and 5 per cent yeast treated citrus fruits upto 45 days. Use of garlic extract and yeast maintains the quality of citrus fruits, prolonged the shelf-life and delayed the rottenness presence on fruits. Penicillium digitatum could grow between temperature ranges of $20^{\circ} \mathrm{C}$ to $45^{\circ} \mathrm{C}$, however, optimum temperature was $27 \pm 1^{\circ} \mathrm{C}$ at which growth and sporulation of the fungus was maximum.
\end{abstract}

How to view point the article : Shinde, R.P., Barhate, B.G. and Musmade, N.A. (2016). Efficacy of garlic extract and yeast against Penicillium digitatum causing post harvest fruit rot of citrus (Citrus sisnensis L.). Internat. J. Plant Protec., 9(2) : 460-463, DOI : 10.15740/HAS/ IJPP/9.2/460-463. 